\title{
La utilización de imanes en la recuperación de la estabilidad de dos tallas en madera: metodología y criterios
}

Sonia Santos Gómez | Dpto. de Pintura y Conservación-Restauración, Universidad Complutense de Madrid

URL de la contribución <www.iaph.es/revistaph/index.php/revistaph/article/view/4150>

\section{RESUMEN}

En la conservación de bienes culturales, y más específicamente de esculturas, es fundamental la estabilidad, ya que de la ausencia de esta cualidad puede derivarse su colapso y algunas patologías, como la aparición de fendas, craquelados y levantamientos de la policromía. En la recuperación de esta estabilidad, como ocurre en general en los tratamientos de conservación aplicados a las obras, se debe mantener como premisa fundamental el empleo de materiales y metodologías que tengan en cuenta los criterios de reversibilidad y discernibilidad de los mismos.

Como ejemplo de lo mencionado, el presente trabajo muestra los trabajos de conservación desarrollados sobre dos esculturas que Gómez-Moreno, en su Catálogo Monumental de España. Provincia de Ávila (1900-1901), definió como "restos de un retablo de escuela de Berruguete".

Se trata de dos esculturas realizadas en madera policromada, que representan a la Virgen y a San Juan Evangelista. Están custodiadas en la sacristía de la iglesia parroquial de San Juan Bautista, en el pueblo de Muñosancho (Ávila). Las policromías han sido realizadas mediante la técnica del dorado al agua y estofados esgrafiados.

En cuanto a su estado de conservación, las obras presentaban importantes fendas en el soporte, así como una gruesa capa de suciedad superficial y lagunas en la policromía con riesgo de pérdidas. Por otra parte, existían amplias faltas volumétricas en la base de las esculturas, que daba lugar a que fueran susceptibles de colapso. Este último tipo de deterioro y su subsanación son los temas principales de este artículo.

\section{Palabras clave}

Conservación | Esculturas | Imanes | Madera policromada | Reconstrucción | Volumetría | 


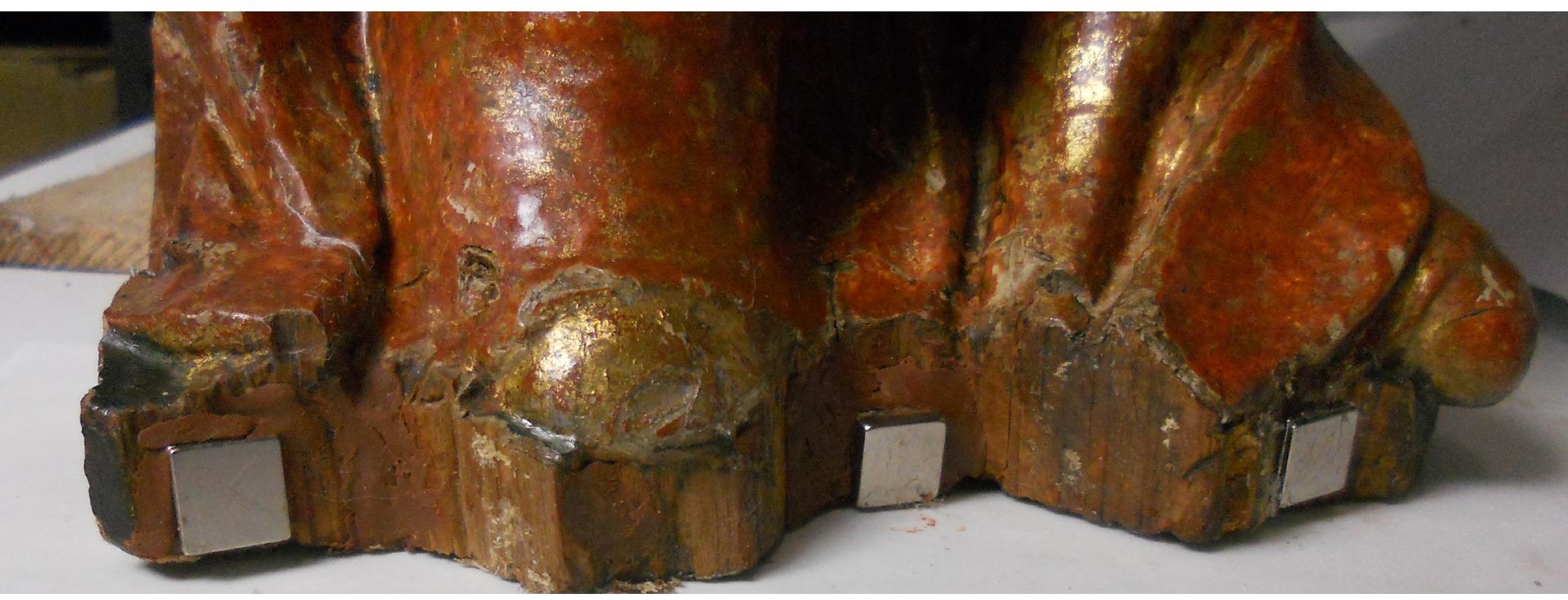

The use of magnets in the recovery of the stability of two sculptures in wood: methodology and criteria

\section{ABSTRACT}

The stability of carvings is one of the main issues in the conservation of cultural heritage, since its lack may have important consequences. In relation to stability, as in conservation treatments in general, the employment of materials and methodologies that try to maintain the criteria of reversibility of the materials used during the treatment must be taken as a premise. As an example of this, the present work shows the works of conservation developed on two carvings that Gómez-Moreno, in his Monumental Catalogue of Spain. Province of Avila (1900-1901), proposed as made by Alonso Berruguete's workshop. These are two sculptures carved in polychromed wood, that represent the Virgin and St. John Evangelist. They are exposed in the sacristy of the parish church of San Juan Baptizer, in Muñosancho (Avila). The polychromy has been applied using the technique of water gilding and esgrafiado. The conservation of both carvings was poor. They had fissures in the support, as well as a thick layer of surface dirt and risk of losses in the polychromy. On the other hand, the existence of wide lacks in the base of the sculptures could produce their collapse. For all this, the recovery of the stability of both carvings is considered essential.To accomplish this aim, we decided to make prostheses of resin, which are fixed to the original one by using powerful magnets. This technology is being used increasingly in conservation of sculptural heritage. This way, we achieve that the volumetric elements (prostheses), added to help the carving recover its stability, are discernible from the original sculpture and the restoration is reversible.

\section{Key words}

Conservation | Sculptures | Magnets | Polychromed wood | Reconstruction | Volumetry |

Cómo citar: SANTOS GÓMEZ, S. (2019) La utilización de imanes en la recuperación de la estabilidad de dos tallas de madera: metodología y criterios. Revista PH [en línea], n. ${ }^{\circ}$ 97, junio 2019, pp. 44-59 <www.iaph.es/revistaph/index.php/revistaph/article/view/4150>

Enviado: 07/04/2018 | Aceptado: 16/04/2019 | Publicado: 28/06/2019 


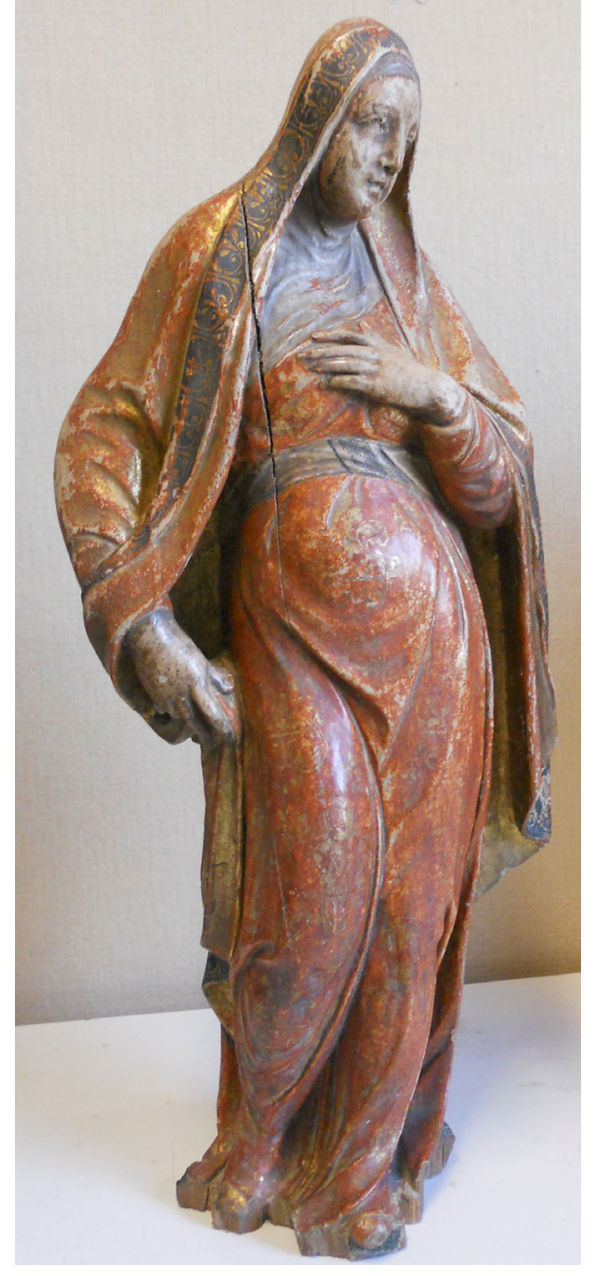

La Virgen. Estado inicial | fotos Sonia Santos Gómez, autora de todas las imágenes que ilustran este texto, si no se indica lo contrario

\section{INTRODUCCIÓN}

Las esculturas policromadas de la Virgen y San Juan Evangelista que alberga la sacristía de la iglesia parroquial de San Juan Bautista de Muñosancho (Ávila) han permanecido durante cientos de años custodiadas por los vecinos del lugar, que desde siembre admiraron su hermosa factura, a pesar de las profundas huellas que el tiempo ha ido imprimiendo en ellas.

Existía la tradición de que correspondían a la mano de Alonso Berruguete, seguramente debido a que ya el historiador Manuel Gómez-Moreno, en su catálogo de la provincia de Ávila, hace referencia a ellas en los siguientes términos (MORENO, 1900-1901: 366):

"Restos de un buen retablo de escuela de Berruguete, consistentes en entablamentos, pilastras y cariátides, niños teniendo escudos de los Ávilas, un profeta recostado, de relieve, y varias figuras de mitad de tamaño natural. Quizá procedan del convento de Cardillejo, y formarían parte del mismo los otros fragmentos que hay en Cantiveros. Sagrario del propio estilo, con relieves y mejor de lo ordinario".

Debe puntualizarse, pese a lo indicado, que las tallas seguramente no procedan del convento de Cardillejo, hoy desaparecido, pero situado otrora en una zona próxima al pueblo de Muñosancho, sino que procederían de un retablo realizado ex profeso para la iglesia parroquial del pueblo por parte de Pedro de Salamanca, seguidor aventajado de Alonso Berruguete. María Jesús Ruiz Ayúcar así lo afirma en los Cuadernos Abulenses (RUIZ AYÚCAR, 1998). Se basa en la documentación del Archivo Diocesano referente a la iglesia de Muñosancho. En las cuentas de 1558 se indica:

"Se descargan 23.503 mrs. que dio y pagó a Pedro de Salamanca, entallador, vecino de Ávila, en parte del pago de los mrs. que ha de haber de la talla del retablo de la dicha iglesia que hizo para la dicha iglesia, lo cual se pagó en dineros y en 15 fanegas de trigo y 30 de cebada del año de 1557 años".

Volviendo a las indicaciones de Gómez Moreno, de los restos referidos en su inventario, aún permanecen en la sacristía de la iglesia el entablamento mencionado, el sagrario y las dos esculturas, que en la actualidad ya han sido restauradas y constituyen las obras cuyo tratamiento de conservación será descrito en el presente trabajo.

Presentaban las esculturas un estado de conservación deficiente. Además de fendas, craquelados, desgastes en la policromía y gran cantidad de suciedad superficial, existían importantes faltas volumétricas en la base, que daban lugar a su inestabilidad y, en consecuencia, a que se temiera por su 
colapso cuando eran exhibidas o manipuladas por la persona encargada de su vigilancia en la sacristía.

Cuando se realizó el planteamiento de conservación de las tallas se contempló que, si esa inestabilidad no se subsanaba, provocaría la potenciación de patologías ya existentes, como el surgimiento de nuevas fendas, craquelados y pérdidas de policromía, o incluso de nuevos fragmentos de madera. Por ello, en cuanto al planteamiento general de conservación, se estableció como premisa fundamental que las esculturas recuperaran esa estabilidad perdida. Razón por la cual, de todo el tratamiento realizado, en este trabajo se detalla y hace mayor hincapié en esta fase de reconstrucción, como se verá en sucesivos epígrafes.

En el proyecto de conservación de las esculturas, se ha considerado primordial, como debe ocurrir normalmente en los tratamientos aplicados a bienes culturales, el empleo, en lo posible, de materiales de reversibilidad ampliamente contrastada y compatibles con la materia que configura la obra original (Bruquetas; Carrasón; Gómez, 2003: 13-48; Deschamps, 2002).

En la labor de devolver la estabilidad perdida a las tallas, ha tenido que reconstruirse el perímetro de la base. Para evitar que la intervención se convirtiera en un falso histórico, se planteó que los elementos volumétricos añadidos fueran discernibles del original y su ubicación reversible. A tal fin, se pensó en utilizar imanes potentes como nexo entre las reintegraciones volumétricas y la obra.

\section{DESCRIPCIÓN DE LAS ESCULTURAS Y DE SU ESTADO DE CONSERVACIÓN}

Como se ha indicado, las esculturas objeto de tratamiento han sido realizadas en madera policromada. De acuerdo a Gómez-Moreno, pueden considerarse "de mitad de tamaño natural" aproximadamente. En concreto, las medidas de San Juan son: 74 × 23,5 x 14 cm y las de la Virgen: 74 × $30 \times 14$ $\mathrm{cm}$.

Se trata de dos imágenes de bulto redondo, con la parte posterior sin tallar, que sólo aparece desbastada. Aparentemente, para su configuración, fue unido un reducido número de piezas de madera. Los resultados del TAC realizado a la imagen de San Juan indican que se compone de tres piezas de madera, mientras que la Virgen consta de cuatro. Puede decirse que, fundamentalmente, se han utilizado dos troncos, uno para cada talla, y a ellos el artífice que talló las esculturas adecuó la forma o posición de los miembros de las mismas, terminando de conformar los ademanes de los personajes mediante el encolado de esas otras pequeñas piezas. La madera no es de

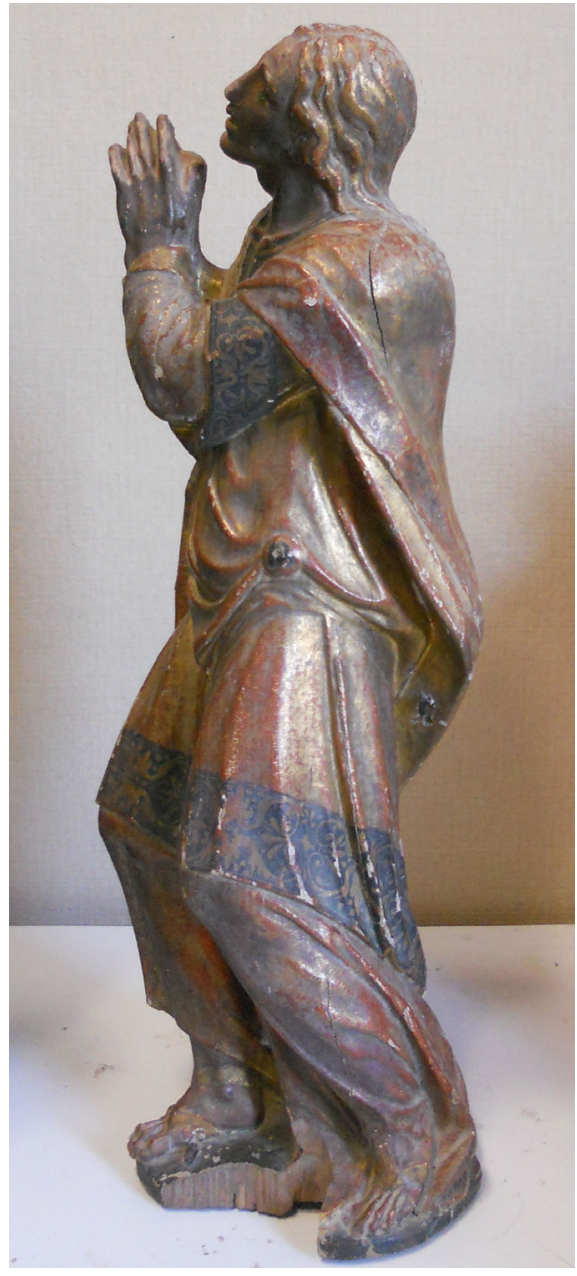

San Juan Bautista. Estado inicial 


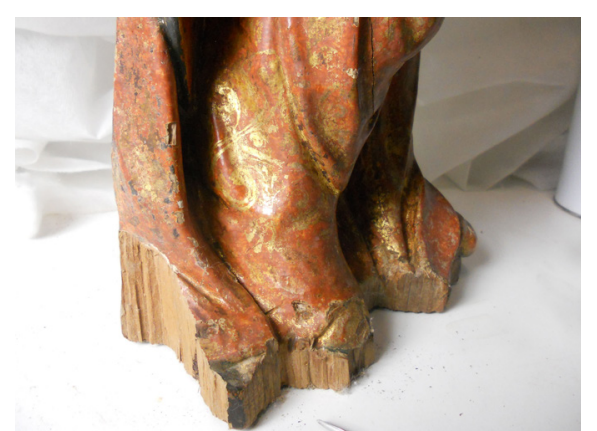

La Virgen María. Detalle del estado inicial. Se aprecian las pérdidas de madera en la base y la existencia de las fibras marcadas que darían lugar a los enganches mencionados durante el proceso de reconstrucción si no se hubieran tomado las medidas oportunas
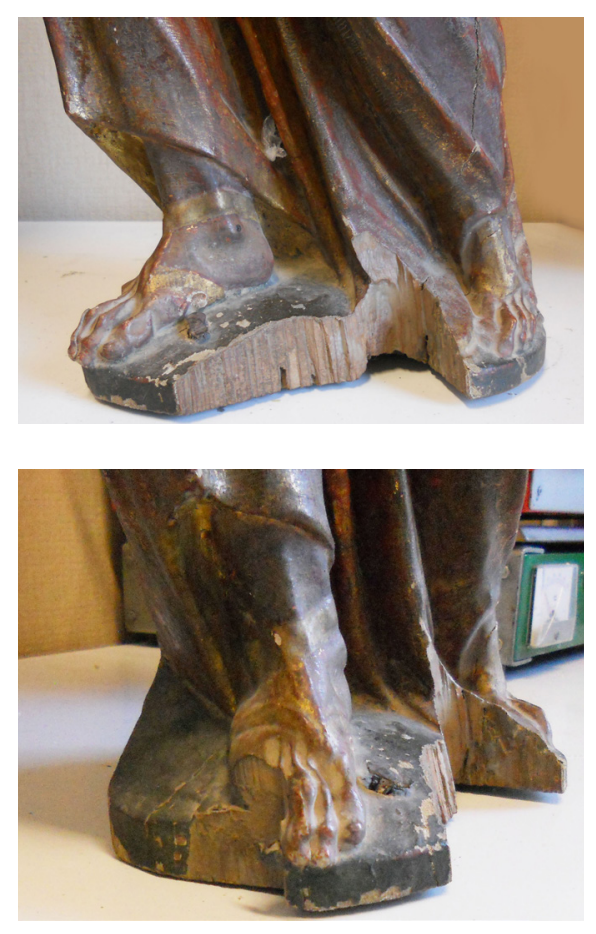

San Juan Evangelista. Detalle del estado inicial, donde se aprecian las pérdidas de madera en la base
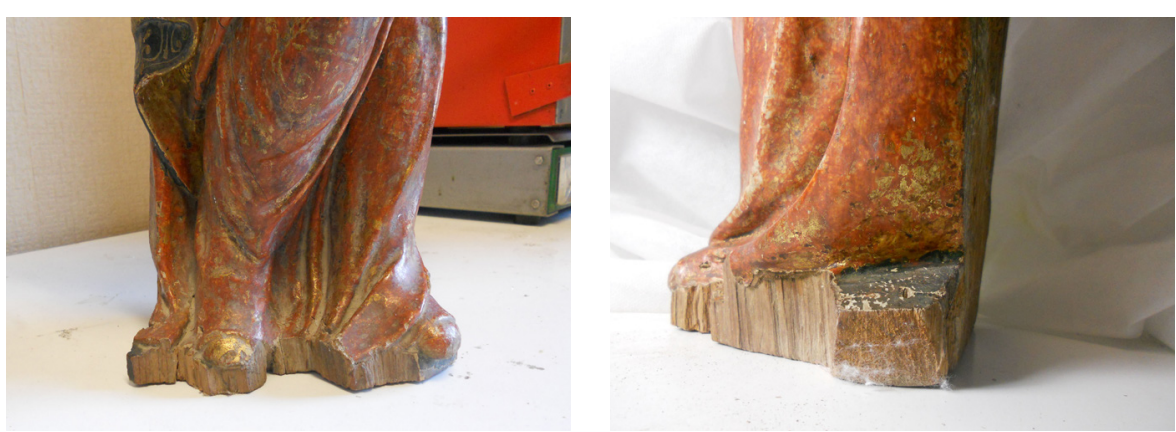

calidad, especialmente en el caso de la Virgen y, posiblemente, para su talla, se aprovecharon los restos que quedaron tras la realización de las otras partes del retablo, ya que las esculturas estarían alejadas de la vista al estar situadas en el ático, con lo que no podía apreciarse desde abajo la escasa bondad de la madera empleada. Así, la talla de la Virgen presenta nudos de grandes dimensiones de los que parten algunas fendas. En la época en que fueron ejecutadas las obras, ya se consideraba que la presencia de nudos en la madera constituía un defecto, tal y como se indica en numerosos contratos concertados para llevar a cabo la talla de los retablos.

Por otro lado, las obras han sido enlenzadas. Se aprecian estos lienzos de refuerzo en la zona de juntas de las piezas de madera, aplicados para reducir los movimientos de ésta y asegurar las uniones. San Juan presenta uno de esos lienzos en su parte posterior. Además, se observaban piezas de tela en numerosas zonas donde existían pérdidas de policromía de esta escultura, con lo que también se piensa que la talla, si no fue enlenzada en su totalidad, sí lo fue en gran parte (CARRASÓN, 2004).

Respecto a la Virgen, no presenta enlenzados en su parte posterior, en la zona de unión entre fragmentos de madera. Sólo un punto de la vestimenta, en concreto una laguna en la policromía de su manto, revelaba la presencia de lienzos de refuerzo, esta vez en su cara anterior. La ausencia de un enlenzado más general ha propiciado sin duda la aparición de las grandes fendas citadas en la escultura, a lo que ha contribuido también la presencia de los nudos, como se ha indicado.

Y debe destacarse, fundamentalmente, en lo que concierne al soporte, que los apoyos de las esculturas presentaban importantes pérdidas que derivaban en su inestabilidad. En el caso de San Juan, las faltas afectaban incluso al pie derecho de la figura.

En cuanto a estas pérdidas, los desprendimientos de los fragmentos de la madera no han dado lugar a planos limpios, sino que las fibras de la madera son patentes y ello da lugar a la existencia de múltiples enganches cuando 
se realiza el proceso de reconstrucción. Este es un hecho que hubo de ser tenido en cuenta a la hora de desarrollar la metodología empleada en la fase de conservación de las obras.

Respecto a las sencillas policromías, quizás, lo más reseñable, en el caso de la Virgen, sean los estofados esgrafiados del orillo del manto, del cinturón, el velo y la túnica rojiza, de la cual se ha perdido gran parte de la veladura superior que arrastró en su pérdida el oro subyacente. En el caso de San Juan, se observan estofados en las mangas de una prenda interior, también en la parte inferior de la túnica talar (aunque de este quedan escasos restos) $y$ en el orillo inferior y bordes de las mangas de lo que parece una prenda o vestidura de encima. Ambas tallas presentan en común el azul muy oscuro que orla los bordes $u$ orillos de las vestimentas. Probablemente la policromía fuera llevada a cabo por Cristóbal de Portillo, tal y como se indica en el Archivo Diocesano de Ávila (RUIZ AYÚCAR, 1998).

Por otra parte, en cuanto al estado de conservación de las policromías, existían ciertas diferencias entre ambas esculturas. Por una parte, la figura de San Juan presentaba una gruesa capa de suciedad superficial de aspecto negruzco que también podía ser observada en la talla de la Virgen, pero en menor medida. Es posible que esta capa oscura derivara, en parte, de un incendio que tuvo lugar en la sacristía, donde han permanecido las esculturas durante largos años. Respecto a la figura de la Virgen quizás el fuego se desarrolló lejos de ella o, lo que es más probable, seguramente la talla fue limpiada posteriormente con algún producto agresivo, lo que derivó en resultados nefastos para la obra, ya que contribuyó a los desgastes que presenta la policromía. Estos desgastes afectan en gran medida a las encarnaciones,
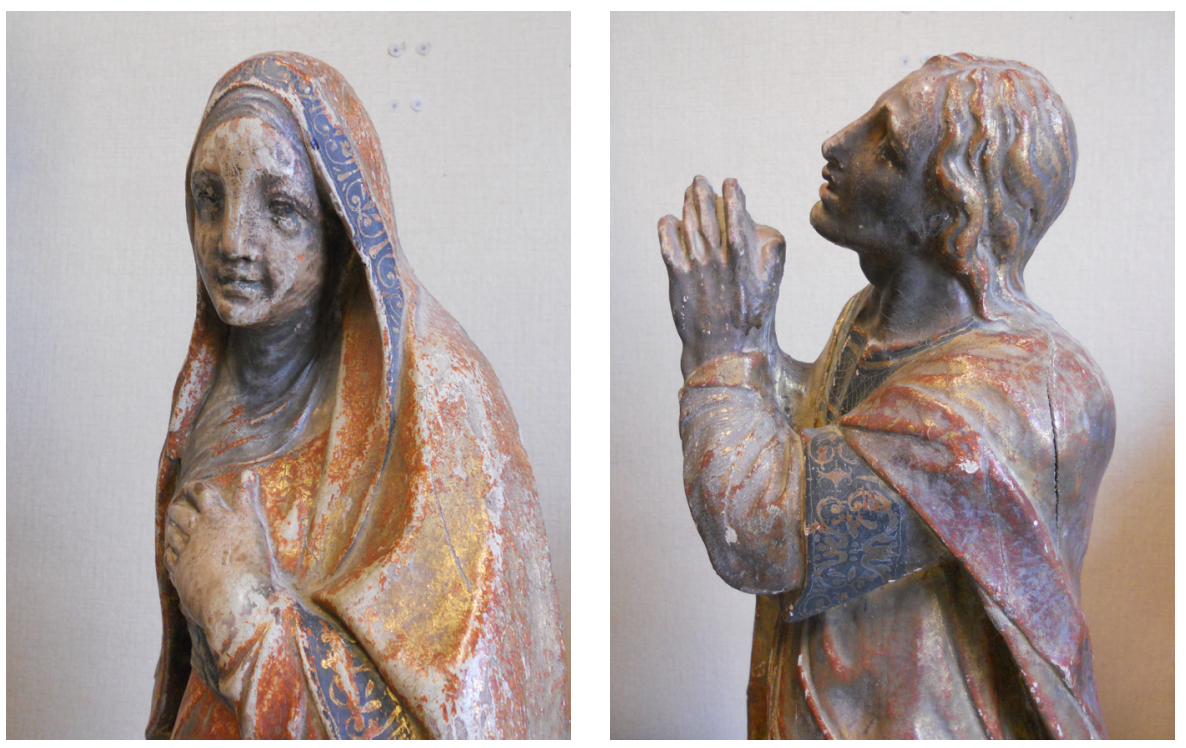

La Virgen María y San Juan Evangelista. Detalle del estado inicial, donde se aprecian las pérdidas de policromía y suciedad superficial 
sobre todo a la correspondiente a la zona del rostro, donde puede apreciarse incluso la madera.

Es posible que las encarnaciones hayan sido realizadas a pulimento, de acuerdo a la época en que fueron ejecutadas. Estas obras habrían sido policromadas en 1559, según los datos que aparecen en el Libro de Fábrica del Archivo Diocesano, en concreto en las cuentas de 1561-62 (RUIZ AYÚCAR, 1998). El tipo de encarnación a pulimento se efectúa al óleo y aparece en la primera mitad del siglo XVI aunque, de acuerdo a Ana Carrasón, puede aparecer y desaparecer a lo largo del siglo (CARRASÓN, 2016).

Por último, respecto al estado de conservación de las esculturas, puede decirse que en ambas se han detectado restos de barniz oxidado.

\section{PLANTEAMIENTO PROPUESTO Y TRATAMIENTO DE CONSERVACIÓN LLEVADO A CABO}

En cuanto al tratamiento de conservación propuesto, como ya se señaló en la introducción, se ha considerado fundamental el restablecimiento de la estabilidad a las esculturas, mediante la utilización de metodologías y materiales perfectamente compatibles con la obra y reversibles.

Además de esta fase de la conservación, que será detallada más adelante, exponemos en una tabla resumen (en la p. 51) todos los procesos del tratamiento aplicado a las esculturas.

De todas estas fases, a continuación será descrita la n..$^{\circ}$, correspondiente a la reconstrucción volumétrica de las bases que ha devuelto la estabilidad a las esculturas.

\section{Realización de prótesis para la base de las esculturas}

La parte fundamental del planteamiento de conservación de las esculturas incluyó los pasos encaminados a devolverles la estabilidad, ya que ambas eran proclives al colapso, como se ha indicado con anterioridad.

El hecho de devolverles ese equilibrio perdido supone añadir partes faltantes que el conservador-restaurador ha de recrear. Estos añadidos no se han contemplado como elementos plenamente integrados en los originales, sino de manera que su ubicación fuera completamente reversible, a fin de que puedan distinguirse las partes añadidas de las originales. Por ello, se plantea una reconstrucción lo más inocua posible, inventando mínimamente las formas, de modo que las partes faltantes sencillamente continúen las existentes pero de tal manera además que las prótesis puedan ser retiradas en 

estratigráfico.

2 Limpieza del reverso de las esculturas mediante el empleo de etanol.

Limpieza de la policromía. Se empleó el sistema de limpieza desarrollado, entre otros, por R. Wolbers y P. Cremonesi, que consiste en emplear siliconas como medio protector de la superficie antes de realizar una limpieza acuosa. En concreto, se ha empleado un tipo de siliconas con 5 grupos Si-O que se denominan D5. Se las supone inocuas para el conservador (Lagalante; Wolbers, 2016; Stavroudis, 2015).

3 Estas siliconas protegen la superficie y la ponen en contacto con microgotas de la solución acuosa limpiadora elegida, que limpia la capa superficial pero no es difundida en el interior de la capa ni extrae componentes. En este caso, después de aplicar D5 sobre la superficie a limpiar, se probó el empleo de métodos acuosos (por ejemplo un tensoactivo como Tween 20 preparado al $2 \%$ en agua) y se obtuvieron resultados satisfactorios. El hecho de que existieran restos de barniz también ha favorecido el éxito de la limpieza sin ocasionar daños al original. En la limpieza se emplearon también mezclas de etanol/éter de petróleo a fin de eliminar el barniz mencionado.

4 Barnizado con barniz de retoques Winsor \& Newton (elaborado con resina cetónica) a fin de proteger la policromía (zonas doradas) para posteriormente llevar a cabo la fase de fijación de color en base a un adhesivo acuoso.

Fijación de color: utilización de cola animal, espátula térmica, Melinex®.

Eliminación de clavos.

Enchuletado, de ambas esculturas, con madera blanda de chopo y coletta. No se ha utilizado resina epoxídica en este proceso. Se consideró especialmente necesaria esta fase en la escultura de la Virgen, que presentaba fendas muy abiertas. Para ello, no se ha retirado madera original de las esculturas, sino que se han ido introduciendo finas láminas blandas en las fendas, que se han adherido unas a otras mediante coletta.

Por otra parte, no se han retirado los nudos apreciables en la parte posterior de la imagen de la Virgen, debido a que su presencia no ocasiona pérdidas en la policromía y forman parte de la materialidad de la escultura.

Realización de la reconstrucción volumétrica de las bases

Estucado-desestucado de todas las partes de la escultura que lo han requerido. El estuco ha sido realizado con yeso mate comercial mezclado con cola animal.

Eliminación del barniz de retoques mediante el empleo de éter de petróleo.

Reintegración cromática con colores Gamblin ${ }^{\circledR}$. Se contemplan como los más idóneos, por la especial estabilidad que se otorga a la resina de urea-aldehído que constituye el aglutinante de los pigmentos (Dunkerton, 2010).

Barnizado final pulverizado (barniz Regal Varnish Gloss), evitando su aplicación en las zonas del estofado azul, a fin de que este mantenga su aspecto mate aterciopelado.

Fases del tratamiento aplicado a las tallas

el momento en que se desee hacerlo. En el desarrollo de esta fase del tratamiento, han primado los criterios de reversibilidad y discernibilidad de lo añadido y evitar el falso histórico, como se comentó en la introducción de este trabajo.

Así, se pensó en utilizar un sistema de unión de las prótesis a base de imanes potentes, de modo que las nuevas piezas pudieran ser retiradas de 


\section{SAN JUAN EVANGELISTA}

N. ${ }^{\circ}$ de imanes: 8

Tamaño: $20 \times 10 \times 0,5 \mathrm{~mm}$

Fuerza sujec. aprox.: 3,8 kg

Temperatura de servicio máx.: $80^{\circ} \mathrm{C}$

Peso: $5 \mathrm{~g}$

\section{VIRGEN MARÍA}

N. ${ }^{\circ}$ de imanes: 10

Tamaño: $10 \times 10 \times 0,3 \mathrm{~mm}$

Fuerza sujec. Aprox.: $1,7 \mathrm{~kg}$

Temperatura de servicio máx: $80^{\circ} \mathrm{C}$

Peso: $2,3 \mathrm{~g}$

\section{N. ${ }^{\circ}$ de imanes: 4}

Tamaño: $10 \times 10 \times 1 \mathrm{~mm}$

Fuerza sujec. aprox.: $600 \mathrm{~g}$

Temperatura de servicio máx.: $80^{\circ} \mathrm{C}$

Peso: $0,76 \mathrm{~g}$

Descripción de los imanes usados para ambas esculturas su ubicación de manera sencilla. Para ello, se tuvieron en cuenta recientes e interesantes publicaciones que se refieren a este tema (RODRÍGUEZ, 2017). Como se ha indicado, los imanes vienen utilizándose cada vez con mayor frecuencia en el ámbito de la conservación, no sólo de pintura, sino también de obra escultórica.

Existen algunos ejemplos, aunque en nuestro país quizás el más conocido, en relación con esta metodología, es el que corresponde a las labores realizadas por el Opificio delle Pietre Dure (Centro de Restauración) de Florencia a la única escultura de Miguel Ángel que se conserva en España. Esta obra, como es sabido, fue realizada en mármol y es propiedad de la Fundación Casa Ducal de Medinaceli-Sevilla. La pieza fue prácticamente destruida a comienzos de la Guerra Civil y ha estado reducida a fragmentos hasta su compleja intervención. La reubicación de las partes reconstruidas se realizó mediante el empleo de imanes.

Por otra parte, debe recordarse que, en el caso de estas esculturas, las roturas de la madera en las bases no eran limpias, sino que presentaban entrantes y salientes que había que solventar a fin de que las prótesis no quedaran enganchadas en las partes originales de las esculturas.

A continuación, se especifican los materiales empleados:

> Imanes: de neodimio comercializados por Superimanes, S.L. (ver cuadro adjunto).

> Plastilina de escultor.

> Barniz de retoques Winsor \& Newton (elaborado con resina cetónica).

$>$ Vaselina filante de la marca Barrero S. L.

> Resina epoxídica Araldite Devcon® 5 minute epoxy.

> Resina epoxídica Araldite SV 427. Indurente NV 427.

> Espátula de escultor.

> Plástico de polietileno.

$>$ Paletina.

$>$ Escofinas y lijas.

Metodología desarrollada. Fases: 


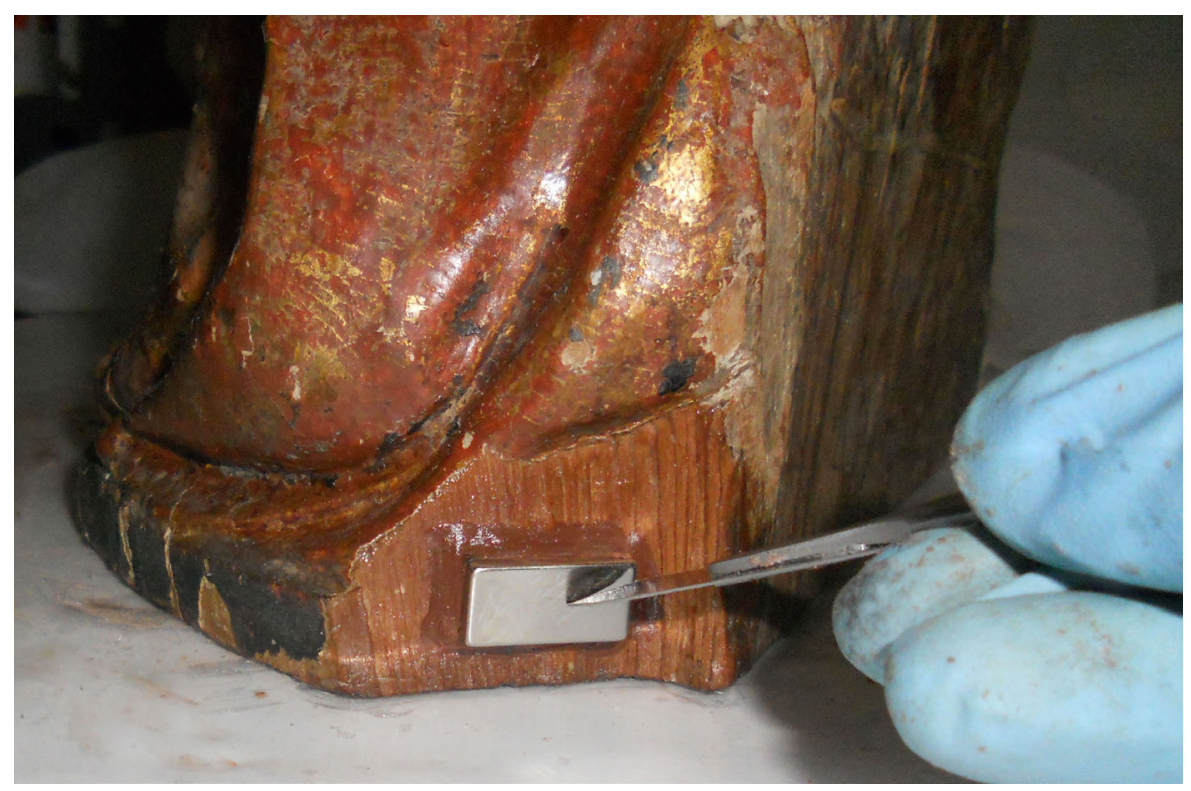

1. El número y morfología de las prótesis diseñadas para cada obra ha sido pensada teniendo en cuenta su durabilidad, así como los enganches que pudieran aparecer entre prótesis y con respecto a la obra original. También se han tenido en cuenta los enganches a la hora de planificar la situación idónea para los imanes. En la escultura de San Juan, han sido realizadas tres prótesis y, para la Virgen, cuatro, una las cuales presentaba un tamaño importante.

Primeramente, se seleccionan los imanes de acuerdo a su número, tamaño y potencia. Para zonas más amplias, bien se coloca un mayor número de imanes, bien han de presentar mayor potencia.

2. La base del imán que vaya a ser adherido a la superficie de la escultura sobre la que va a realizarse la prótesis, ha de ser rayada con bisturí o lija a fin de garantizar una unión estable y duradera entre el imán y la escultura. El adhesivo empleado a tal fin es una resina epoxídica de dos componentes de curado rápido Araldite Devcon® 5 minute epoxy. Otro adhesivo barajado para sustentar los imanes, por su reversibilidad, fue Paraloid B-72, que aparece también en las publicaciones relacionadas con la adhesión de imanes (Rodríguez, 2017). Sin embargo, se descartó su empleo debido a su escasa resistencia a la tracción, que podía derivar en la pérdida final de los imanes.

3. Aplicación de barniz de retoques alrededor del imán en las zonas donde se van a realizar las reconstrucciones, a fin de proteger la superficie de la madera de la vaselina que posteriormente se aplicaría sobre ella. A su vez,
San Juan Evangelista. En la imagen, existen dos imanes superpuestos. Alrededor del que está en contacto con la madera y que permanece oculto, se ha aplicado una línea de plastilina. Además, se está rayando la superficie del segundo imán. Esta cara del imán será aquella sobre la que se aplique resina epoxídica que le adherirá a la prótesis 
La Virgen María. En la imagen de arriba se aprecian los imanes, así como las tiras de plastilina alrededor de los mismos y en otras zonas de la madera donde pudieran existir enganches

Abajo, aplicación de resina epoxídica rápida sobre el imán que una vez curada quedará adherida a la prótesis

A la derecha, aplicación de resina epoxídica en la realización de las prótesis. Encofrados de plastilina
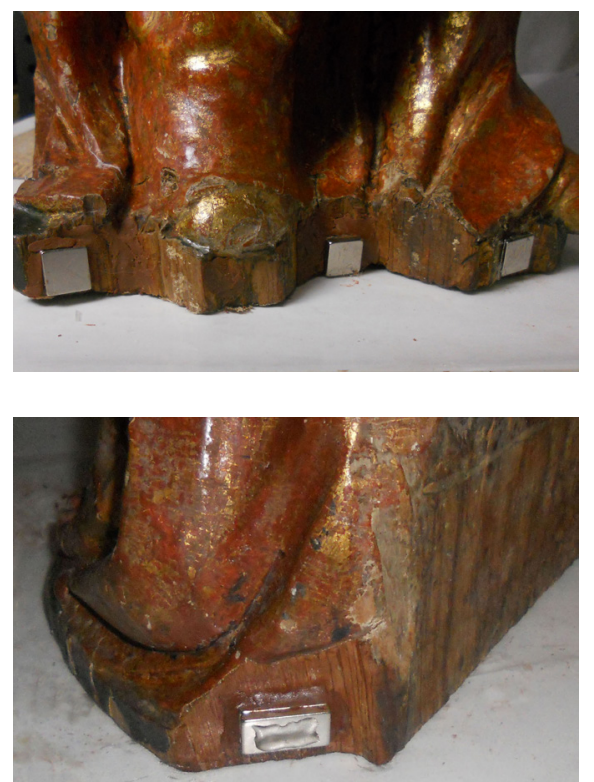

la vaselina evitará que la pieza resultante del modelado quede adherida a la madera una vez haya curado la resina con la que se ha configurado.

4. A continuación, se coloca un imán sobre el anterior. Este segundo imán será el que vaya embutido en la prótesis. Entonces, alrededor del primer imán, el que está en contacto con la madera, se aplica una tira de plastilina mediante el empleo de un espatulín de escultor. Este último paso tiene como fin evitar el enganche de la reconstrucción volumétrica en el imán que está adherido a la obra.

La plastilina ha sido aplicada también en todas las zonas de las esculturas donde se preveía podrían quedar enganchadas las prótesis utilizadas en la reconstrucción. Como se ha indicado, en las zonas de faltas, los planos de las mismas no eran limpios, ya que presentaban zonas de entrantes y salientes. La plastilina evita, por tanto, que la prótesis quede enganchada en estos puntos. Esta plastilina únicamente se mantiene durante el proceso de aplicación de la resina para la realización de las reconstrucciones. Una vez la resina ha curado, se retiran las prótesis y también la plastilina.

5. Después, se raya la superficie del imán que irá embutido en la reconstrucción volumétrica para mejorar su adherencia a la prótesis.

6. Aplicación de desmoldeante, vaselina filante de la marca Barrero, sobre la superficie de la madera barnizada donde se realiza la reconstrucción. Así se evita que la resina empleada en la reconstrucción se adhiera a la madera. Justo antes del momento en que vaya a colocarse sobre él la resina epoxí-

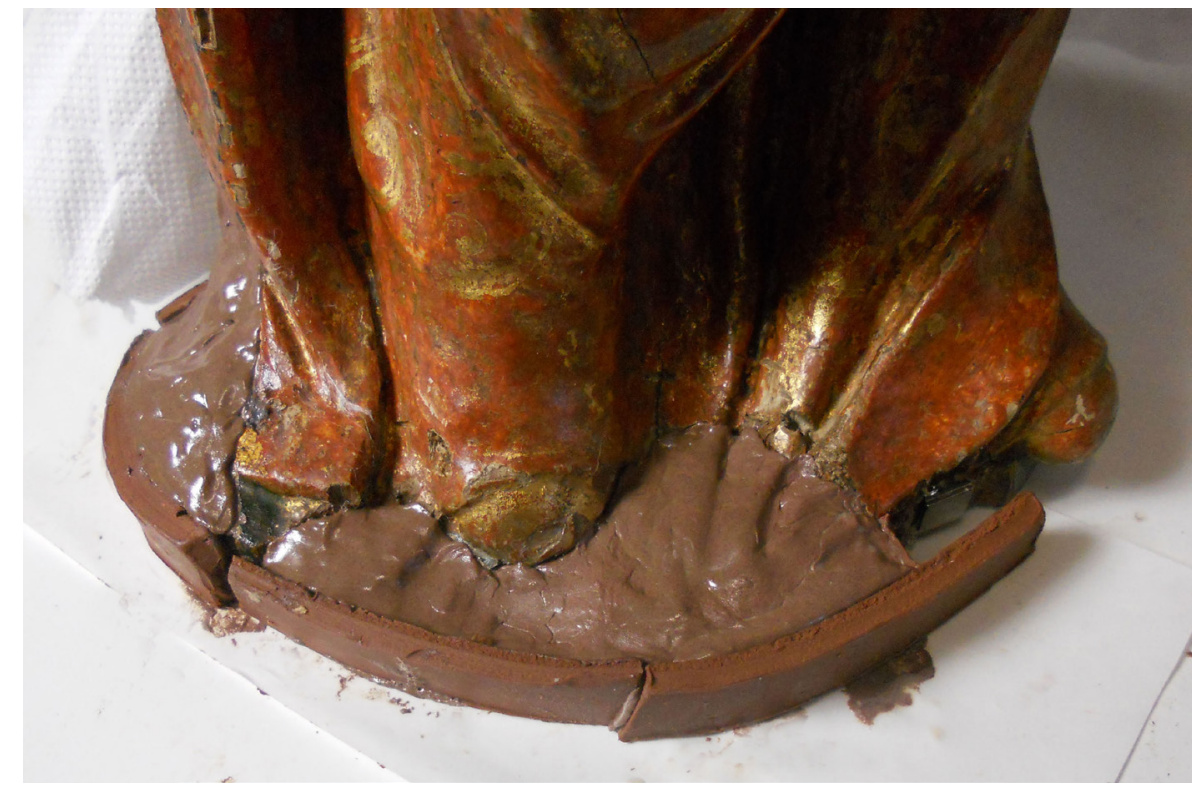



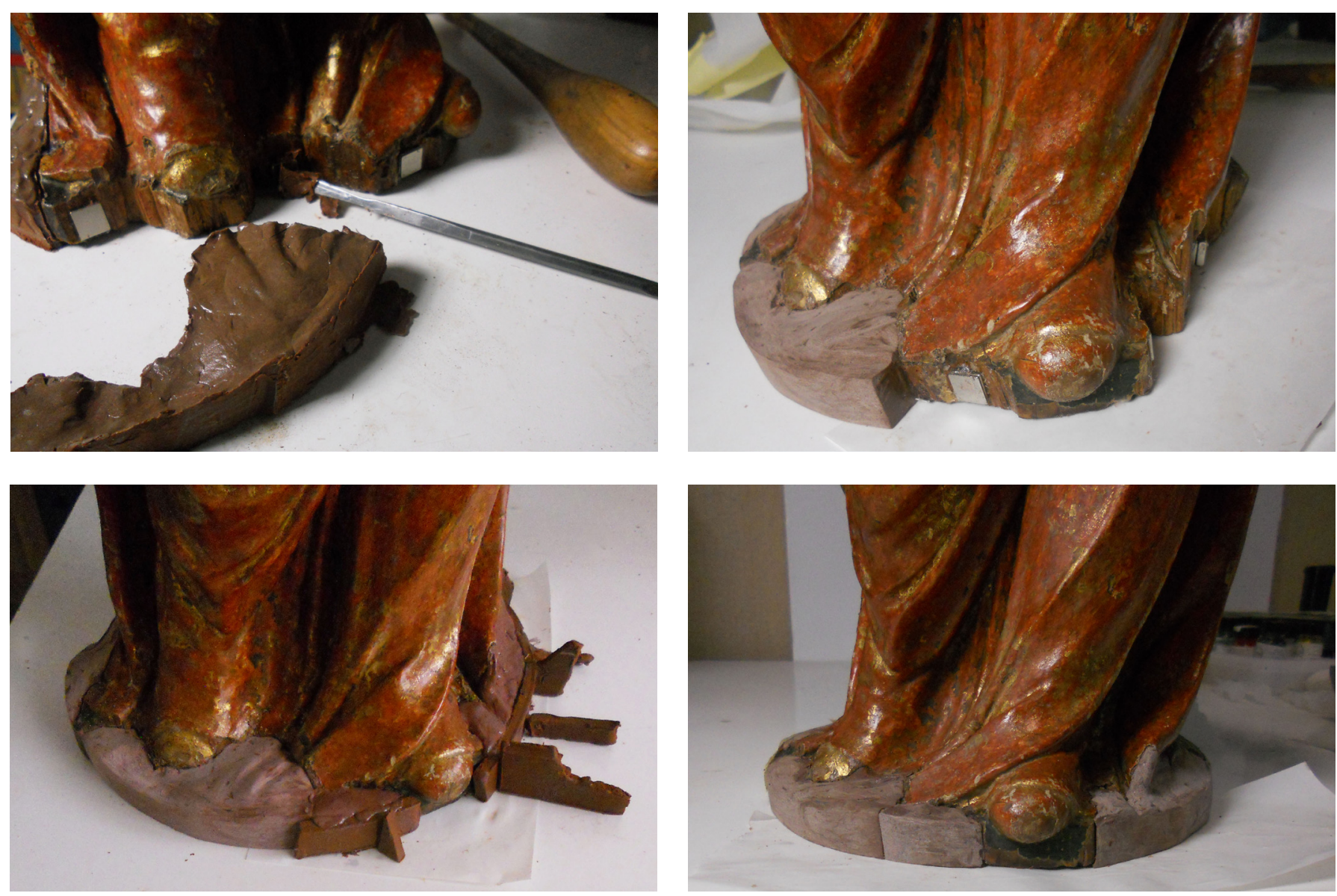

La Virgen María. Arriba a la izquierda, puede observarse que una vez curada la resina, ha sido retirada la prótesis. También se está procediendo

dica empleada en la reconstrucción, se aplicará sobre su parte posterior otra resina, la epoxi de curado rápido que ya fue aplicada en el primer imán que fue adherido a la superficie de madera. Esta resina curará mientras se está aplicando la resina empleada en la reintegración volumétrica y el imán, por tanto, quedará adherido a ésta.

7. Se coloca además un plástico de polietileno de protección bajo la escula la eliminación de la plastilina que ha evitado los enganches. En la siguiente imagen, de arriba a abajo, de izquierda a derecha, se aprecia que la prótesis ya ha sido trabajada con escofinas y lijas. En la siguiente, se están realizando dos prótesis más y la resina aplicada se sujeta con encofrado y contrafuertes de plastilina. En la última se observan ya todas las prótesis después de que ha curado la resina y han sido trabajadas mediante lijas y escofinas tura. Se trata de evitar que la resina Araldite, empleada para realizar las prótesis, se adhiera a la mesa. El polietileno es un plástico al que no se adhiere la mayoría de los adhesivos y resinas (entre las que se encuentran las epoxídicas). También se han colocado papeles siliconados para esta finalidad.

8. Poco a poco van realizándose las partes faltantes. La resina empleada en la reconstrucción es Araldite SV 427 y su endurecedor Indurente HV 427. Se mezcla con su endurecedor y se modela con palillos. También se emplea un encofrado de plastilina para contener la resina. 
Una vez curada, se retiran las prótesis y sus formas son trabajadas mediante el empleo de lijas y escofinas.

9. Una vez han sido realizadas las prótesis, se retira la plastilina, vaselina y el barniz de retoque aplicados sobre la madera. Para ello, se utilizan espatulines e hisopos con disolventes impregnados en éter de petróleo y, posteriormente, en acetona.

10. A continuación y, como se ha indicado, se estuca con estuco de yeso y cola animal.

11. La reintegración se realiza mediante selección cromática con colores Gamblin ${ }^{\circledR}$ (DUNKERTON, 2010: 92-100). Por último, se barniza la obra, incluyendo las zonas de las prótesis y evitando el brillo en las zonas de estofados.

\section{CONCLUSIONES}

Arriba, estucado de las prótesis. Aspecto final una vez fue realizada la reintegración cromática

Las esculturas objeto de estudio en el presente artículo representan a un San Juan Evangelista y la Virgen María y están realizadas en madera policromada. Se encontraban en un estado de conservación deficiente y el pro-
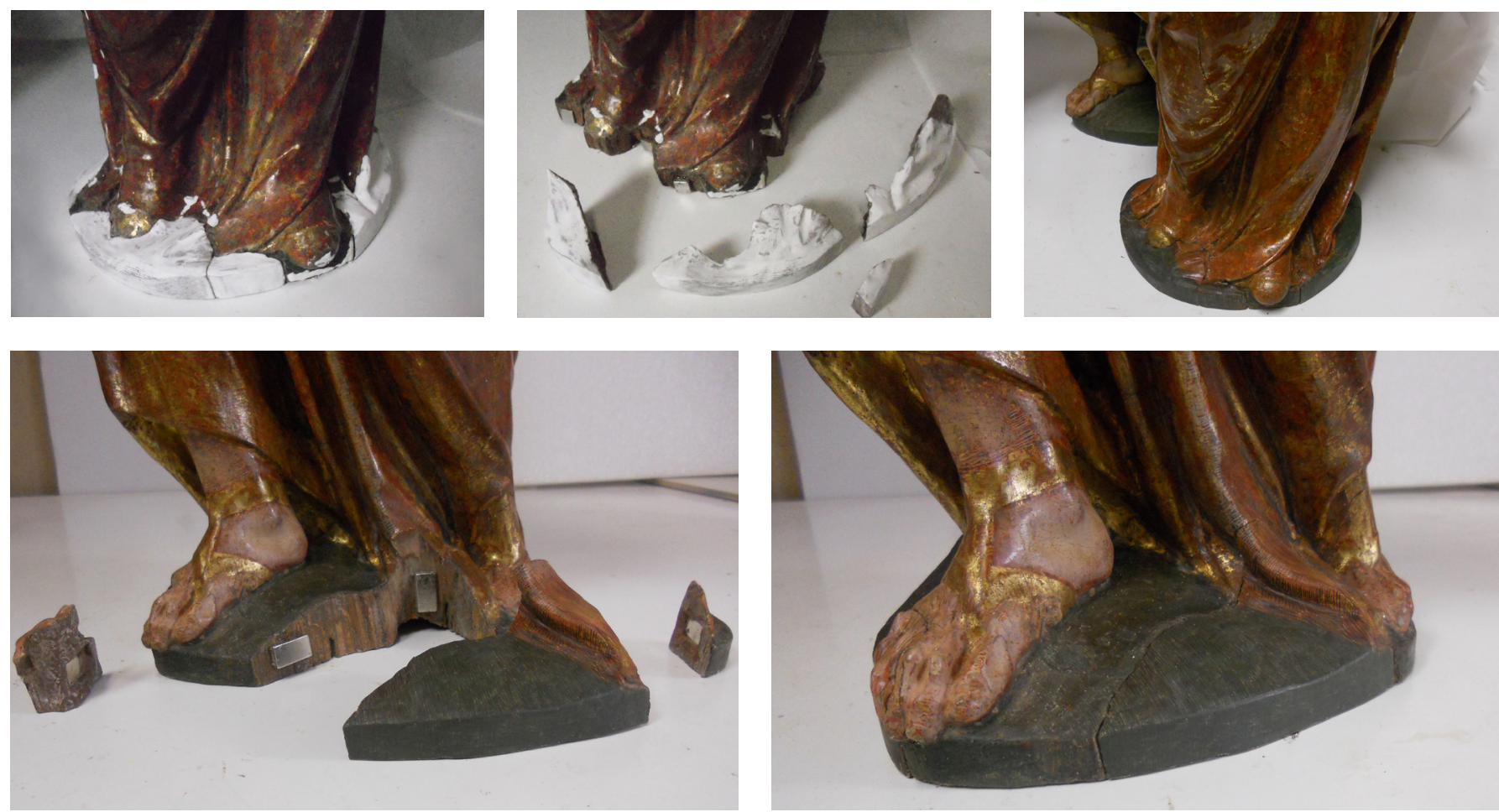

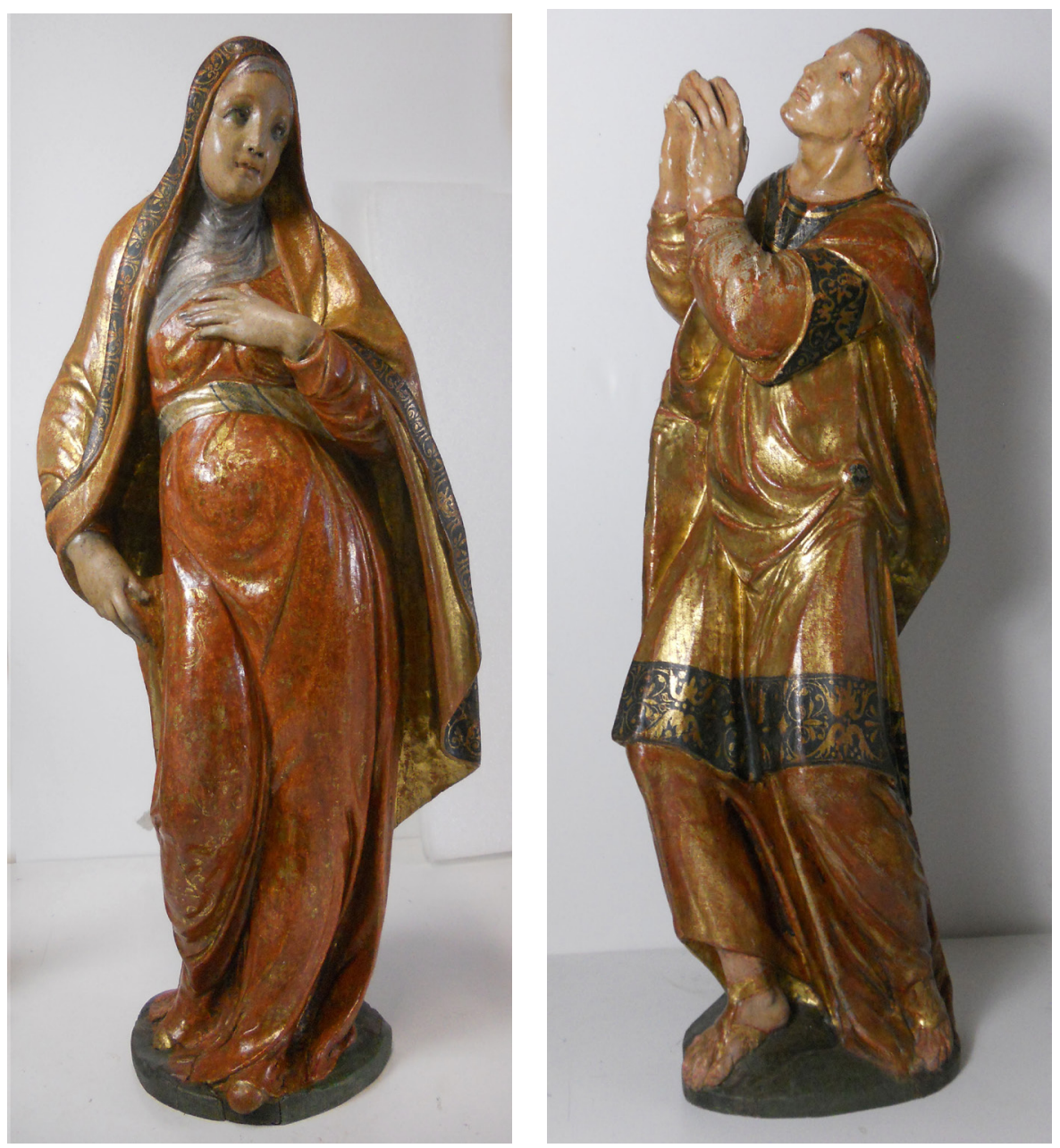

Aspecto final de la Virgen María y San Juan Evangelista

blema más acuciante que presentaban era el de su inestabilidad, por lo que eran proclives al colapso. Esta situación se debía a que los apoyos de las mismas, que corresponden a bases talladas en el tronco de madera en que trabajaron los cuerpos de las imágenes, presentan numerosas faltas volumétricas.

El tratamiento aplicado a estas obras ha sido el habitual para obra de características similares: fijación de color, limpieza, estucado y reintegración cromática. Debe destacarse, sin embargo, de todas las fases del tratamiento, aquella dedicada a reconstruir volumétricamente las bases de las esculturas, a fin de que recuperaran el equilibrio.

Se consideró que una posible solución a la problemática mencionada habría de tener en cuenta que las prótesis aportadas, que tenían que continuar las formas originales y, por tanto, recrear los volúmenes faltantes, no debían sin 
embargo ser fijadas de manera permanente a ambas esculturas. Se trataría, por tanto, de partes que podrían ser removibles y, por tanto, reversibles, a fin de evitar realizar un falso histórico. Por ello, se pensó en la utilización de nexos no fijos entre prótesis y esculturas, en concreto en el empleo de imanes de neodimio para esta finalidad. Además, para configurar las prótesis se contempló el empleo de resina, debido a que se trataba de un material distinto del original (madera). Sobre estas prótesis se ha realizado una reintegración cromática mediante selección cromática, que contribuye a diferenciar la prótesis del original.

En la realización de esta reconstrucción de las bases de las esculturas, se ha tenido en cuenta su peculiar deterioro: las zonas con pérdidas, presentaban fibras muy marcadas con entrantes y salientes donde podían quedar enganchadas fácilmente las prótesis. Este importante inconveniente ha sido solventado mediante la colocación de plastilina en estas zonas, antes de proceder al modelado de las reconstrucciones. De este modo, una vez curada la resina, la plastilina ha sido retirada y se han evitado, por tanto, los enganches de las prótesis en la obra. También ha sido fundamental, para evitar estos enganches, el estudio previo de la ubicación de los imanes en la obra.

Los resultados obtenidos en todo este proceso se consideran satisfactorios, ya que se han conseguido los objetivos perseguidos: devolver la estabilidad a las esculturas pero siembre bajo los criterios de discernibilidad y reversibilidad de los materiales empleados. Por todo ello, se considera que la metodología aplicada podría ser reproducida en esculturas de naturaleza similar y aquejadas de una problemática de conservación también análoga.

\section{Agradecimientos}

El presente trabajo de investigación ha contado con la financiación de diferentes proyectos, como el art. 83 n. 155 que lleva por título Expertización de una talla de San Juan Evangelista atribuida a Alonso Berruguete. Planteamiento y ejecución de su proceso de conservación-restauración, con el también art. 83 n. ${ }^{\circ} 156$ Expertización de una talla de la Virgen María atribuida a Alonso Berruguete. Planteamiento y ejecución de su proceso de conservación-restauración y con el proyecto financiado por el Ministerio de Ciencia e Innovación Materiales poliméricos de origen sintético. Nuevos usos y en el que participa la UCM.

La autora también quiere expresar su agradecimiento a Jesús María Parrado del Olmo, Sonia Tortajada Hernando, José Luis Santana González, Sergio Rubia Portero y al Obispado de Ávila, especialmente a Ceferino Jiménez Díaz y Jesús López Martín. 


\section{BIBLIOGRAFÍA}

- BRUQUETAS, R.; CARRASÓN, A.; GÓMEZ, T. (2003) Los retablos. Conocer y conservar. Bienes culturales: revista del Instituto del Patrimonio Histórico Español, n. ${ }^{\circ} 2$, 2003, pp. $13-48$

- CARRASÓN, A. (2004) Construcción y ensamblaje de los retablos en madera. En Los Retablos: Técnicas, Materiales y Procedimientos (CD). Valencia: GEIIC, 2004

- CARRASÓN, A. (2006) Las encarnaciones y algunas reflexiones sobre sus tratamientos. Pátina, época II, n. ${ }^{\circ} 13-$ 14, 2006, pp. 87-93

- DUNKERTON, J. (2010) Retouching with Gamblin Conservation Colors. En ELLISON, R.; SMITHEN, P.; TURNBULL, R. (eds.) Mixing and Matching, Approaches to Retouching Paintings. London: Archetype Publications, 2010, pp. 92-100

- DESCHAMPS, F. (dir.) (2002) Metodología para la conservación de retablos de madera policromada. Sevilla: Consejería de Cultura, The Getty Conservation Institute, 2002

- GARCÍA CHICO, E. (1959) Nuevos documentos para el estudio del arte en Castilla. Escultores del siglo XVI. Valladolid: Universidad de Valladolid, 1959

- GÓMEZ-MORENO, M. (1900-1901) Catálogo monumental de España. Provincia de Ávila

- JIMÉNEZ PÉREZ, E. (2012) Proyecto de intervención en el Retablo Mayor de la Iglesia de la Magdalena de Valladolid, obra de Esteban Jordán. Trabajo fin de máster inédito, Universitat Politècnica de València, 2012

- LAGAlANTE, A. WOlBERS, R. (2015) The Cleaning of Acrylic Paintings. New Particle-based water-in-oil Emulsifiers. En SELVA, V. E. (ed.) Atti del VII Congresso Internazionale Colore e Conservazione Dall'olio all 'acrilico, dall 'Impressionismo all 'Arte Contemporanea. Milán: II Prato, 2015

- PACHECO, F. (1990) Arte de la pintura (ed. prínc. 1649, ed. actual, int. y $n$. de Bonaventura Bassegoda i Hugas). Madrid: Cátedra, 1990

- RODRígueZ, M. A. (2017) Análisis de Sistemas Magnéticos Aplicados a Uniones de Fragmentos. Tesis doctoral inédita, Universitat Politècnica de València, 2017 <doi:10.4995/Thesis/10251/90522>

- RUIZ, M. J. (1998) Nuevos datos para la biografía del escultor Pedro de Salamanca. Cuadernos abulenses, n. ${ }^{\circ}$, 1998, pp. 265-291

- SANTOS, S. (2017) El empleo de las tecnologías 3D en la conservación del patrimonio y su aplicación en la realización de reproducciones de bienes culturales. Observar, 11 (1), 2017, pp. 97-114
- STAVROUDIS, C. (2015) Silicone-Based Solvents in Conservation. As free solvents and components of gel systems and microemulsions. En SELVA, V. E (ed.) Atti del VII Congresso Internazionale Colore e Conservazione Dall'olio all 'acrilico, dall 'Impressionismo all 'Arte Contemporanea. Milán: II Prato, 2015 